\title{
A review on travel behaviour modelling in dynamic traffic simulation models for evacuations
}

\author{
Adam J. Pel • Michiel C. J. Bliemer • Serge P. Hoogendoorn
}

Published online: 28 January 2011

(C) The Author(s) 2011. This article is published with open access at Springerlink.com

\begin{abstract}
Dynamic traffic simulation models are frequently used to support decisions when planning an evacuation. This contribution reviews the different (mathematical) model formulations underlying these traffic simulation models used in evacuation studies and the behavioural assumptions that are made. The appropriateness of these behavioural assumptions is elaborated on in light of the current consensus on evacuation travel behaviour, based on the view from the social sciences as well as empirical studies on evacuation behaviour. The focus lies on how travellers' decisions are predicted through simulation regarding the choice to evacuate, departure time choice, destination choice, and route choice. For the evacuation participation and departure time choice we argue in favour of the simultaneous approach to dynamic evacuation demand prediction using the repeated binary logit model. For the destination choice we show how further research is needed to generalize the current preliminary findings on the location-type specific destination choice models. For the evacuation route choice we argue in favour of hybrid route choice models that enable both following instructed routes and en-route switches. Within each of these discussions, we point at current limitations and make corresponding suggestions on promising future research directions.
\end{abstract}

Keywords Evacuation - Travel behaviour - Departure time choice - Destination choice · Route choice · Dynamic traffic simulation

\footnotetext{
A. J. Pel $(\bowtie) \cdot$ M. C. J. Bliemer · S. P. Hoogendoorn

Department of Transport and Planning, Faculty of Civil Engineering and Geosciences,

Delft University of Technology, P.O. Box 5048, 2600 GA Delft, The Netherlands

e-mail: a.j.pel@tudelft.nl

M. C. J. Bliemer

e-mail: m.c.j.bliemer@tudelft.nl

S. P. Hoogendoorn

e-mail: s.p.hoogendoorn@ @udelft.nl
} 


\section{Introduction}

Society is forced to deal with many natural and man-made disasters. These hurricanes, wildfires, floods, large storms, mudflows, terrorist attacks, chemical spills, industrial accidents, and many similar hazards cause massive economic and social damage as well as loss of lives every year. Studies, such as those by Hooke (2000) and Newkirk (2001), show that the frequency and intensity of natural disasters has been increasing over the past decades. Furthermore, other studies, such as those by Plowman (2001) and Barrett et al. (2000), argue that due to the population and urban development growing faster than road infrastructure capacity, mass evacuations will become increasingly more difficult and time consuming. This underlines the importance for hazard prone regions to invest in efficient disaster management strategies. Such strategies can focus on avoidance, where precautionary measures reduce the probability of such disasters (e.g., reinforcing dams, raising dikes, clearing fire control lines), or mitigation, where responsive measures reduce the impact of such disasters (e.g., evacuation). Lave et al. (1990) uses explicit cost-benefit analyses to show that the responsive option of evacuation allows preserving peoples' lives at much lower costs. Nevertheless, in a later study (Lave and Apt 2006) it is argued that authorities might be reluctant to actually order an evacuation when warranted due to the uncertainty, lack of experience, and fear of financial liability involved in the process of evacuation.

The success of an evacuation strongly depends on many factors, such as warning time, response time, information and instructions dissemination procedure, evacuation routes, traffic flow conditions, dynamic traffic control measures, etc. (Dash and Gladwin 2007; Lindell and Prater 2007). Given the complexity of the underlying processes and the multitude of factors influencing these procedures, traffic simulation models are helpful or even indispensible for the analysis and planning of emergency evacuations (Barrett et al. 2000; Hardy et al. 2010). These traffic simulation models can be applied to obtain a better understanding of the evacuation conditions and the effect of traffic regulations and control measures hereon, by predicting departure and arrival patterns, travel times, average speeds, queue lengths, traffic flow rates, etc. Insight into this dynamic process is necessary to make founded decisions on, for instance, the latest possible time to start evacuation, the best evacuation routes, or the most suitable traffic management measures.

This contribution elaborates on the different (mathematical) model formulations underlying these traffic simulation models used in evacuation studies and the behavioural assumptions that are made. We look at both (commercial) traffic simulation models used in evacuation studies as well as evacuation research and proposed model formulations. The focus lies on how travellers' decisions regarding the choice to evacuate, departure time choice, destination choice and route choice are modelled. Hence, this review article is complementary to other state-of-the-art review articles on aspects such as how these traffic simulation models are used to evaluate and design optimal evacuation instructions and management strategies (e.g., Yusoff et al. 2008; Abdelgawad and Abdulhai 2009), the issues that must be dealt with once implementing these evacuation plans in practice (e.g., Wolshon et al. 2005a, b), the data requirements to manage and model emergency situations (e.g., Wilmot et al. 2009; Henson et al. 2009), and driving behaviour under adverse conditions (e.g., Hoogendoorn 2010). In the ensuing discussion we consider the car as the main mode of transport for evacuation. In this view, this review article is complementary to other state-of-the-art review articles on other modalities of transport, for instance, pedestrian evacuation research (e.g., Schadschneider et al. 2008). Many of the evacuation modelling and simulation issues relating to car travel behaviour also relate to evacuation by 


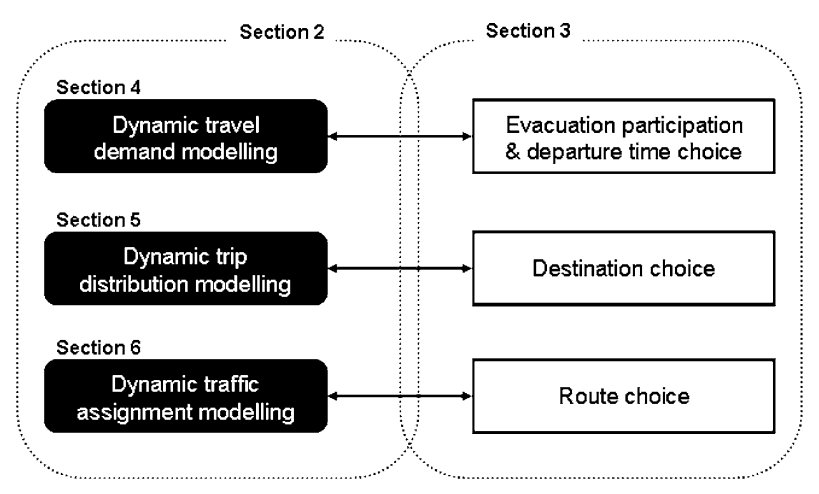

Fig. 1 Framework evacuation traffic simulation model and outline article

public and organized transport, as well as multimodal evacuation. However, these modes of transport will not be discussed explicitly.

Figure 1 shows the framework of a typical dynamic traffic simulation model that can be used in evacuation studies. Here, the black boxes on the left-hand side represent the model components: dynamic travel demand model, dynamic trip distribution model, and dynamic traffic assignment model. The white boxes on the right-hand side indicate the behaviour that is described by each of these model components: evacuation participation and departure time choice, destination choice, and route choice. The outline of the article follows this model framework as follows. We start with giving an overview of the history of evacuation simulation models and the current state of the practice in "Past and current evacuation traffic simulation models" section. After that, we discuss in "Traveller behaviour under evacuation conditions" section, the current view on travellers' choice behaviour in case of evacuation, making reference to both a number of empirical studies on evacuation behaviour as well as insights from the behavioural sciences related to decision making under emergency conditions. Then sections "Travel demand modelling", "Trip distribution modelling" and "Traffic assignment modelling" form the main body of this article, elaborating on the (implicit) assumptions regarding traveller behaviour that are generally made in evacuation traffic simulation models or proposed model formulationsincluding those models discussed in "Past and current evacuation traffic simulation models" - in light of the view presented in "Traveller behaviour under evacuation conditions" section. More precisely, we discuss travel demand modelling (i.e., travellers' evacuation and departure time choice decisions) in "Travel demand modelling" section. We discuss trip distribution modelling (i.e., travellers' destination choice decisions) in "Trip distribution modelling" section. And we discuss traffic assignment modelling (i.e., travellers' route choice decisions) in "Traffic assignment modelling" section. Each of these sections ends with a critical discussion on current practices and promising future research directions. The final section then gives a concluding discussion on the main findings and makes some final remarks.

\section{Past and current evacuation traffic simulation models}

In the late 1970s, a number of simulation models were developed to analyze and evaluate emergency evacuation plans. Early studies in the 1980s focused mainly on evacuation in 
case of nuclear power plant emergency due to the Three Mile Island reactor incident in 1979. Then, after a number of extremely devastating hurricanes hitting the coast line of the U.S. in the 1990s, much evacuation modelling research shifted focus to hurricane evacuation. Since the September 11, 2001, incident in the U.S., also mass evacuation due to terrorist attacks is getting more attention. Due to tsunamis in China and wildfires in Australia over the past years, evacuation research in these countries focus on these types of evacuation. For the Dutch situation, rising sea levels and a perceived increasing threat of flooding has led to the start of a national program initiating flood evacuation research and applications within the Netherlands.

In many of the early studies, evacuation is recognized as an exceptional event regarding different travel demand patterns, driver behaviour, traffic management, etc., resulting in new traffic models being developed specifically for evacuation studies. A few examples are NETVAC (Sheffi et al. 1980), DYNEV (KLD 1984), MASSVAC (Hobeika and Jamei 1985; Hobeika and Kim 1998), TEDSS (Sherali et al. 1991), IMDAS (Franzese and Han 2001), OREMS (Rathi and Solanki 1993), and CEMPS (Pidd et al. 1993). Some basic model characteristics and applications of these models are listed in Table 1. A note can be made here that TEDSS is set up as a decision support system based on the simulation model MASSVAC, which in turn can be seen as a successor of NETVAC. And OREMS is based on the microscopic traffic simulation model CORSIM, which is developed for regular day-to-day traffic conditions. These early simulation models are typically developed and customized for the evacuation of specific regions in response to a specific type of hazard. For instance, NETVAC is designed to plan evacuation in response to a nuclear power plant accident and therefore models the evacuation of all inhabitants from a predetermined area (10 miles radius from plant site) in radial outward direction, while MASSVAC is developed for hurricane evacuation of a rural area and requires evacuation routes as model input from all origin locations to all safe destinations, where the origins and destinations depend on the projected path of the hurricane. A distinguishing feature of DYNEV which is worth mentioning is that it is the only model listed in Table 1 where multimodal evacuation can be simulated, although in a limited form. Car and bus transport are incorporated, where bus services are modelled explicitly by route, schedule, and stop locations. Earlier models that have also been applied more recently and on reasonably large scale are DYNEV (e.g., Goldblatt 2004; Wolshon et al. 2005a) and OREMS (e.g., Han and Yuan 2005; Li et al. 2006; ORNL 2002).

More recently, a large number of evacuation studies are conducted using well-established dynamic traffic simulation models developed for regular day-to-day traffic

Table 1 Early evacuation traffic simulation models and their characteristics and applications

\begin{tabular}{|c|c|c|c|c|c|c|}
\hline \multirow[t]{2}{*}{ Model } & \multicolumn{2}{|c|}{ Traffic representation } & \multicolumn{2}{|c|}{ Time dimension } & \multicolumn{2}{|c|}{ Application } \\
\hline & Micro & Macro & Static & Dynamic & Offline & Online \\
\hline NETVAC & & $\mathrm{x}$ & $\mathrm{x}$ & & $\mathrm{x}$ & \\
\hline DYNEV & & $\mathrm{x}$ & & $\mathrm{x}$ & $\mathrm{x}$ & \\
\hline MASSVAC & & $\mathrm{x}$ & $\mathrm{x}$ & & $\mathrm{x}$ & \\
\hline TEDSS & & $\mathrm{x}$ & $\mathrm{x}$ & & $\mathrm{x}$ & \\
\hline IMDAS & $\mathrm{x}$ & & & $\mathrm{x}$ & $\mathrm{x}$ & \\
\hline OREMS & $\mathrm{X}$ & & & $\mathrm{x}$ & & $\mathrm{x}$ \\
\hline CEMPS & $\mathrm{x}$ & & & $\mathrm{x}$ & $\mathrm{x}$ & \\
\hline
\end{tabular}


applications, including both microscopic models, such as PARAMICS (Cova and Johnson 2003), CORSIM (Williams et al. 2007), VISSIM (Han and Yuan 2005), and INTEGRATION (Mitchell and Radwan 2006), and mesoscopic or macroscopic models, such as DYNASMART (Murray-Tuite 2007), DynaMIT (Balakrishna et al. 2008), DynusT (Noh et al. 2009), TransCAD (Wang et al. 2010), and INDY (Klunder et al. 2009). In a number of studies using microscopic models, model parameters describing driving behaviour (such as headway, acceleration, reaction time) have been adjusted for the case of emergency evacuation (e.g., Tu et al. 2010). Other than that, the model structure and parameter settings are typically not changed.

In all these models the origin-destination travel demand is either model input or is computed using a gravity-model based trip distribution model, or a combination of the two. The departure times are generally determined by applying an exogenous response curve stating the percentage of departures in each time interval. Such a response curve has been assumed to follow a number of different distributions (e.g., Uniform distribution, Poisson distribution, and Weibull distribution). A user-defined dynamic origin-destination matrix allows evaluating (mandatory) evacuation instructions regarding dedicated departure time windows and destinations.

These trips are then in most models assigned to the road network according to the (dynamic or static) user-equilibrium assignment assumption, where one may wonder whether an equilibrium assumption will hold in an emergency evacuation. Exceptions are the few models (OREMS, MASSVAC, and VISSIM) where user-defined routes can be model input, thus allowing evaluating (mandatory) instructions regarding prescribed evacuation routes. Other exceptions are the route choice models incorporated in INTEGRATION and DYNASMART allowing en-route route switching based on prevailing traffic conditions.

In most models, traffic flow is simulated in which road network characteristics are mostly static. In some models road network characteristics such as capacity and maximum speed vary to incorporate the damaging effect of the hazard on the road infrastructure (e.g., links becoming less accessible due to flooding) and dynamic traffic management and control measures (e.g., contraflow operations to increase outbound capacity). For example, MASSVAC allows modelling several consecutive time intervals (time-sliced static traffic assignment) in which road network characteristics change, and INDY incorporates socalled 'events' in which network characteristics and model parameters can vary in time.

A final addition to this overview of prior and current evacuation traffic models is the development of decision support systems and traffic information systems which are integrated with a dynamic traffic simulation model. For instance, the Evacuation Traffic Information System ETIS (PBS\&J 2000a) is set up as a web-based monitoring tool for collection and distribution of traffic information during the process of evacuation. ETIS uses real-time information from different sources on, for example, evacuation participation rates, traffic management and control measures, prevailing traffic conditions, and weather conditions. The tool then predicts traffic conditions for a short time ahead based on historic evacuation data, and evaluates the effect of applying traffic control measures such as contraflow and lane closures. ETIS has been applied in practice in the south eastern states of the United States, including North Carolina, South Carolina, Georgia, and Florida, and later also Alabama, Mississippi, Louisiana, and Texas (Wolshon et al. 2005a).

We should remark here that this overview of past and current evacuation traffic simulation models does not aim to be complete, but to provide a framework of the current practices in traffic simulation models used in many evacuation studies. Here we only discussed the more 'full fledged' traffic simulation models. A number of interesting 
proposed model formulations in evacuation research will be introduced and discussed in "Travel demand modelling", "Trip distribution modelling" and "Traffic assignment modelling" sections when we elaborate on the individual model components of a typical evacuation traffic simulation model.

\section{Traveller behaviour under evacuation conditions}

The models introduced in the previous section aim to simulate traffic conditions on a road network in case of evacuation. They thereby unavoidably make assumptions on how travellers may behave in these types of conditions. To allow us to investigate the suitability of these behavioural assumptions in the following sections, we will here discuss the viewpoint of the behavioural sciences on evacuation travel choice behaviour and show how empirical studies on evacuation behaviour underline or question this view.

Before discussing the psycho-behavioural research and empirics on evacuation behaviour, two notes can be made here. First of all, there exists quite an extensive amount of literature in the field of behavioural sciences relating to humans' psychological response to, for example, (imminent) emergency conditions, and decision making under timepressure and safety concerns (for an overview see Court et al. 2004; Dombroski et al. 2006; Mawson 2005). This kind of research has found almost no reference in evacuation traffic modelling and simulation studies. This might be partly due to its often non-quantitative or experimental set up. Second of all, remarkably enough, in contrast to network evacuation modelling, in crowd evacuation modelling, surprisingly many simulation models attempt to incorporate more realistic human behaviour. This is done by extending these pedestrian simulation models to more sophisticated agent frameworks. For instance, applying cognitive-behavioural frameworks to model individuals' behaviour under specific conditions (e.g., the so-called belief-desire-intension framework is often applied), or different structures are built-into model leadership and herding behaviour, or travellers' information acquisition and exchange is modelled to include possible unfamiliarity and learning characteristics (see e.g., Murakami et al. 2002; Pelechano et al. 2005; Pelechano and Badler 2006; Shendarkar et al. 2006).

Psycho-behavioural research and empirics on evacuation behaviour

A large number of real life emergency situations collected and discussed by Quarantelli (1957) and Leach and Campling (1982) indicate that the behavioural response of people is remarkably consistent across different types of disastrous conditions. This structural pattern is divided into a number of temporal phases showing how behavioural responses change over time as the emergency conditions develop, summarized in Fig. 2. These phases range from pre-impact when an emergency is becoming probable to post-impact

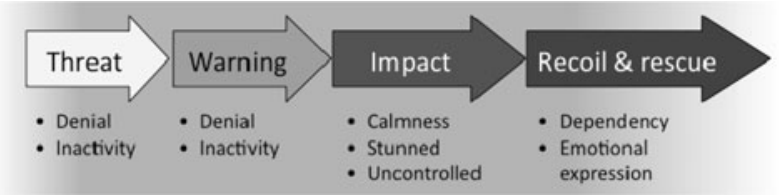

Fig. 2 Phases in emergency conditions and their most prevalent behavioural responses (from Hoogendoorn et al. 2009, based on Leach and Campling 1982) 
when the emergency has passed. Equivalent models have been proposed by, for example, Glass (1959) and Tyhurst (1951). The main value of this framework is that each phase is accompanied by a specific behavioural response which is found to be then predominantly prevailing.

An equivalent dynamic approach focusing on the individual decision-making task states, that individuals experience a number of (quasi-)consecutive psycho-behavioural phases. The decision-making task starts with information acquisition, followed by situation assessment, and finally action execution (first posed by Woodworth 1958). Since individuals cannot assess all available information, the first two phases are undertaken simultaneously (Baddeley 1972; Wickens 1987). Information is filtered based on relevance and trustworthiness according to how the current situation is perceived. This filtering process makes the task easier, however may delay accepting and appropriately responding to changing conditions. This can be explained through the phenomenon of cognitive dissonance. For example, when people perceive themselves as safe yet receive information on a possible threat, then the logical inconsistency in these beliefs is (initially) resolved by rejecting or ignoring this warning information. A large number of real life examples are discussed by Leach and Campling (1982) where people in danger choose to ignore the possibility of the disaster despite the warnings prior to the disaster. In all cases, the conflicting information is discarded as being not relevant or untrustworthy.

This pattern of behaviour is resembled by the findings in a number of empirical studies specific to evacuation. For instance, Mileti et al. (1975) reports that the more information the initial warning contains, the more likely it is that people respond. And, when warnings are heard and believed, then evacuation is the end result. This is also underlined by the findings of Baker (1991). Twenty-six post-hurricane surveys in the period 1961 till 1989 in the US indicated that next to factors such as risk level, public instructions, housing type, and storm threat, the personal risk perception was most prominent in the decision whether to evacuate. Similarly for the case of cyclones in Australia, Raggatt et al. (1993) found that people with less warning time were more likely to deny their personal risk and reside in a general feeling of complacency. De Jong and Helsloot (2010) report on the results from surveys held during a Dutch national exercise on flood evacuation. In this study, a large share of people (48-66\%) remains unaware of the actual risk while warning is given and voluntary evacuation is advised. At the same time, the credibility of the information that is given is deemed low by the majority (52-88\%). A very informative discussion on this topic is given by Dash and Gladwin (2007). One of their statements is that it is the perception of risk that motivates people to evacuate, not the hearing of warnings and evacuation orders. This is implied by the psycho-behavioural frameworks constructed in the behavioural sciences, as well as a strikingly common finding in many empirical studies.

Once the danger is recognized and people start responding, their information processing and decision making capabilities might be limited due to mentally demanding circumstances, associated with anxiety and (the perception of) time-pressure. Wills (1998) argues that in these situations people rely more on instincts and experience, thereby avoiding the time needed for making rationally thought-over decisions. Leach and Campling (1982) and Schmidt and Warner (2002) found evidence for this by showing that people typically tend to remain calm, and only once they perceive inescapability do they express behaviour which can be seen as irrational and habitual (note that to express habitual behaviour under disaster conditions, for instance, for the case of exit choice, can be seen as irrational or illogical). Leach and Campling (1982) further argue that during the impact phase there is evidence of a clear distinction between the psycho-behavioural responses of three types of individuals. Once people undertake action in the impact phase, people may remain calm 
and rational, may be stunned by the situation and react in a semi automatic manner, or may mentally breakdown and react uncontrolled and inappropriately. It is found that in most cases approximately $75 \%$ of the individuals express the second type of behaviour, while the behaviour of the remaining share corresponds evenly with the first and third type. It should be noted that although the appearance of egocentric behaviour is widely accepted, especially panicking behaviour has been shown to be quite an uncommon reaction to an emergency situation (Aguirre 2005; Blake et al. 2004; Bohannon 2005; Cornwell 2003; Mawson 2005).

A number of empirical studies on evacuation behaviour show a slightly different pattern. This might have to do with the fact that the circumstances (during the impact phase) which these psycho-behavioural constructs are based on are more imminent than typically seen (or perceived) in these empirical evacuation studies. The surveys by De Jong and Helsloot (2010) in the Dutch flood exercise show that once the actual dike breach and flood occur, the need for information on aspects as the expected flooding area, water height, and possible government aid in the evacuation increased. With a number of people, this lack of information impaired them on making a decision whether to evacuate. Those people that do decide to evacuate show a similar prominent need for information. This need for traffic information on appropriate evacuation routes is reported, for example, by Dow and Cutter (2000) and Lindell et al. (2005) after conducting post-hurricane surveys and by Robinson and Khattak (2010) based on stated preference surveys. In cases where this traffic information is not available, travellers might be impaired in their route decisions. Dow and Cutter (2002) held a survey among South Carolina residents after hurricane Floyd. One of their findings was that, despite the congestion on the main egress routes, travellers did not switch to alternative routes using rural roads. The authors suggest that this might have been due to travellers' uncertainty that alternative (rural) routes would not provide breakdown services and cell phone coverage. Likewise, Lindell and Prater (2006) report that for the case of hurricane Katrina, travellers relied slightly more on past familiarity with the evacuation route than on prevailing traffic conditions, likely due to the lack of traffic information.

The last phase of recoil and rescue (see Fig. 2) will not be discussed here since the evacuation is most likely to have ended by then.

\section{Discussion}

The above perspective on evacuation travel behaviour shows that a number of factors play an important role in determining the travel decisions of individuals. In sum, individuals react according to how they perceive the changing situation. They thereby respond to both the hazard's evolution in space and time, as well as the dynamic traffic (management) conditions, possibly with some delay. This explains the evacuees' need for information. That people do not automatically follow the advice and orders from public officials, but tend to seek information, assess their personal risk, and make independent evacuation decisions, is supported by a substantial number of empirical studies (e.g., Baker 1991, 1995; Dash and Morrow 2001; De Jong and Helsloot 2010; Dow and Cutter 1998, 2000; Knowles 2003; Rasid et al. 2000). It is therefore essential that dynamic traffic simulation models that aim to simulate an evacuation include this reactive traveller behaviour, therewith incorporating the important role of time-varying disaster conditions, (traffic) information, and warnings, discretionary advice and evacuation orders.

We should remark here that, as in "Past and current evacuation traffic simulation models" section, this overview of socio-psychological research and empirics on evacuation 
behaviour attempts in no way to give a complete discussion on all (empirical) research on evacuation behaviour. Instead we wish to provide a background of the current consensus on evacuation behaviour. This background is needed in the following sections when discussing the suitability of the (mathematical) model formulations that are proposed and used to simulate traveller behaviour under evacuation conditions.

\section{Travel demand modelling}

Travel demand models predict the number of people who will evacuate and when these people will depart. In other words, these models describe the decisions of travellers regarding evacuation participation and departure time. These decisions are generally made at the household level (Dash and Gladwin 2007; Dow and Cutter 2000; Heath et al. 2001; Whitehead et al. 2000). We will in the following discussion however not consider at which level the decision is made, but how the resulting evacuation participation rates and departure time patterns are simulated.

A commonly used approach to dynamic travel demand modelling is to do so in two or three consecutive steps. Logically, the first step is to identify the region that needs to be evacuated. The first step of establishing the region that will evacuate or needs to be evacuated is often done by expert judgment going by the hazard scenario characteristics. For hurricane evacuations, this procedure is formalized by Wilmot and Meduri (2005) using hurricane attributes such as the track, speed, and size to identify evacuation zones. Easily identifiable zones (by e.g. ZIP code and landmarks) are then assigned a specific risk and are expected to evacuate in case of specific scenarios. Here, regions above the maximum surge flood limit are not considered. However, evidently, also areas which are in fact not at risk may start evacuating (shadow evacuation). Especially considering the findings in the previous section that evacuation is primarily motivated by people's perception of being at risk. Durham (2007) points out that this may particularly happen during mass evacuations and it would lead to larger travel demand thus hindering those in real need to evacuate.

After the first step is undertaken and the evacuation region is identified, the share of people that will participate in the evacuation is predicted, as well as their departure times. Herein, we distinguish two approaches based on whether the participation and departure time choices are modelled as sequential decisions ("Sequential travel demand model" section) or conducted simultaneously ("Simultaneous travel demand model" section).

Sequential travel demand model

In the sequential approach, once the evacuation region is identified, the second step in predicting travel demand is to predict the share of people who will evacuate. For the case of hurricanes, Baker (1991) listed five attributes determining the decision to evacuate: the risk level within the area, actions by public authorities, type of housing, prior perception of personal risk, and a storm specific threat factor. In the past, these attributes have served for an empirically based approach to predict evacuation demand by Tweedie et al. (1986). Later, PBS\&J (2000b) developed a cross-classification type of trip generation model based on survey data collected in the south-eastern states of the US where the evacuation participation specified by county depended on the hurricane category and speed, tourist occupancy, and type of housing in that area. The performance of this behaviour-based model was tested against a number of data-driven models, namely logistical regression and 
Fig. 3 Evacuation response curve following Weibull distribution for different parameter settings: dashed graph $\beta=0.135, \gamma=2.55$; dashdotted graph $\beta=0.085$, $\gamma=3.05$; solid graph $\beta=0.085$, $\gamma=2.55 ;$ long dash-dotted graph $\beta=0.085, \gamma=2.05$; long dashed graph $\beta=0.035$, $\gamma=2.55$

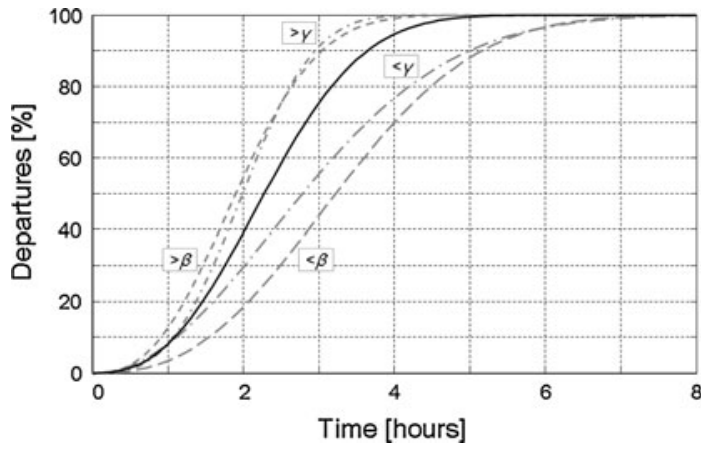

various forms of neural network models, by Wilmot and Mei (2003) on a data set collected in south-west Louisiana following hurricane Andrew. The findings showed that the datadriven models (particularly a feedforward neural network structure) were better able to predict the observed participation rate. The drawbacks of these types of models (especially neural networks) are, however, that they require specific data for calibration and the results are typically not transferable to other settings. This while behaviour-based models do not have these drawbacks and provide more insight into the evacuation participation behaviour of people.

The third step to predict the dynamic travel demand is to model travellers' departure time choice. This is often done by applying an exogenous response curve stating the percentage of departures in each time interval. Since some origins will be earlier under threat than others, such a response curve is typically predicted for each origin separately. The departure response curve has been assumed to follow many different distributions. Some examples are instantaneous departure (Lewis 2001; Chen and Zhan 2004; Chiu et al. 2006), a Uniform distribution (Liu et al. 2006; Yuan et al. 2006), a Rayleigh distribution (Tweedie et al. 1986), a Poisson distribution (Cova and Johnson 2002), a Weibull distribution (Jonkman 2007; Lindell 2008) or sigmoid curve (Kalafatas and Peeta 2009; Xie et al. 2010). The Weibull distribution and sigmoid curve are most often used and claimed to be most realistic. The Weibull distribution is given by

$$
D(t)=1-\exp \left(-\beta t^{\gamma}\right)
$$

where $D(t)$ is the cumulative percentage of people who have evacuated until time instant $t$. The shape of the distribution is determined by two parameters, $\beta$ and $\gamma$. The effect of these parameters is shown in Fig. 3. Higher values for $\beta$ and $\gamma$ lead to a faster response, while lower values represent a slower response. The sigmoid curve is given by

$$
D(t)=(1+\exp [-\alpha(t-h)])^{-1}
$$

The shape of the curve is determined by two parameters, $\alpha$ and $h$. The effect hereof is more distinguishable and allows behavioural interpretation (Fig. 4). The response rate $\alpha$ sets the slope of the curve, such that low values produce a more uniform departure profile (slower response). The half loading time $h$ sets the midpoint of the curve, and thus states the time at which half of the total number of travellers have departed. Sensitivity analyses on these parameters done by Ozbay and Yazici (2006) and Pel et al. (2010b) conclude that advancing or postponing the half loading time $h$ clearly has no impact on the evacuation process since travellers depart at the same rate and thus queue lengths and average travel times are equal for all cases (unless road network characteristics are stochastic or the road 
Fig. 4 Evacuation response curve following sigmoid curve for different parameter settings: long dashed graph $\alpha=2.5$, $h=2.5$; long dash-dotted graph $\alpha=1.5, h=4$; solid graph $\alpha=2.5, h=4$; dash-dotted graph $\alpha=3.5, h=4$; dashed graph $\alpha=2.5, h=5.5$

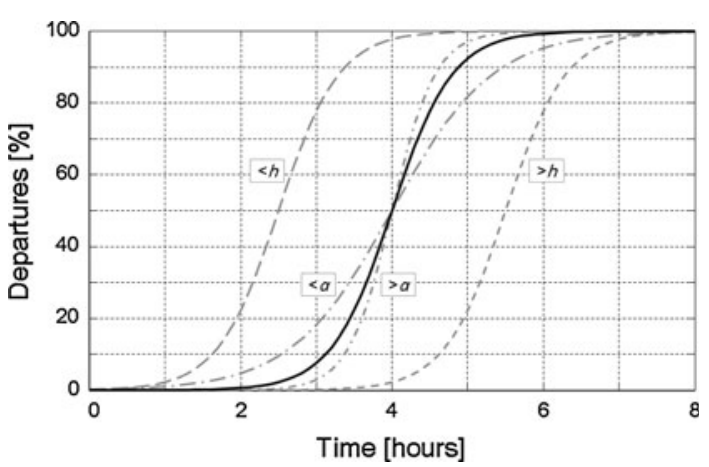

network is not fully available throughout the duration of the evacuation). On the other hand, the response rate $\alpha$ has a substantial non-linear impact on the evacuation traffic conditions and arrival pattern, especially when the network load is relatively high (which can be expected during evacuation conditions). The reason is that a higher response rate leads to more traffic on the road network which results in more congested traffic conditions. These worse traffic conditions lead to lower network performance (measured by, e.g., traffic flow and arrival rates), which in turn further deteriorate network performance. This positive feedback loop implies that a higher response rate does not guarantee a faster evacuation; it may even be slower. This underlines the importance of estimating the appropriate parameters when using these models applying an exogenous response curve.

The sequential approach discussed above is applied most often. Ozbay and Yazici (2006) reason that this is due to the mathematical simplicity of the approach and the fact that relatively little situation-specific data is required. Model attributes and parameters are usually estimated based on expert judgment or past evacuation data. However, the drawback of this sequential approach (and particularly the response curves) is that there is no clear behavioural basis to justify the method on as the response curves are exogenous input instead of endogenously determined by the threat/hazard within the model. It is difficult, if not impossible, to incorporate the findings on the important (socio-psychological and circumstantial) factors determining individuals' evacuation decision as discussed in "Traveller behaviour under evacuation conditions" section. This is also underlined by Fu (2004) pointing out that response curves are typically constructed for short-lasting evacuations (up till several hours, while many evacuations may last for several days), time-ofday variations are not included (the sigmoid curve does not allow incorporating the behavioural effect of day/night time on the departure times which are observed in real-life), hazard specific dynamics known to influence the travel demand are not included (e.g., the speed, intensity and track of a hurricane or wildfire inappropriately have no effect on travel demand), and the effect of an evacuation plan cannot be realistically assessed (since the impact of the evacuation order is not addressed).

\section{Simultaneous travel demand model}

Another approach relaxing many of these limitations is to execute these steps (i.e., predicting trip generation and departure time) simultaneously as an endogenous process. The dynamic travel demand is modelled by applying a repeated binary logit model where we repeatedly in time predict the share of people who decide to evacuate and depart presently, or postpone the decision to evacuate, see Fig. 5. The decision to evacuate, modelled by this 
Fig. 5 Conceptual framework repeated binary logit model

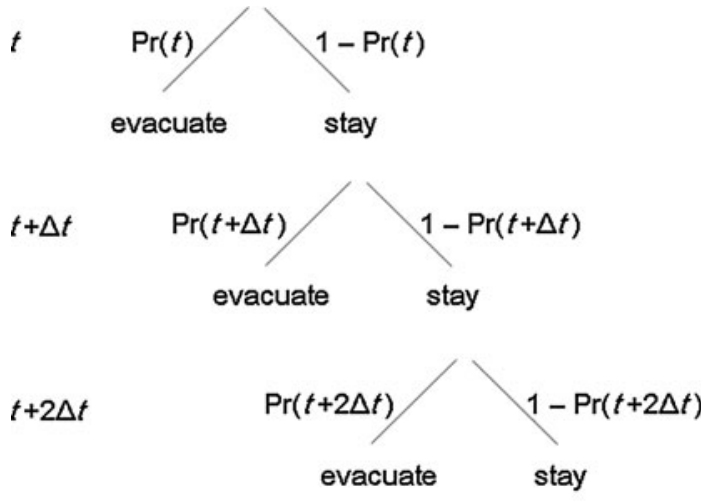

binary logit model, is based on the differential utility associated with evacuating (compared to not evacuating) based on the (subjectively perceived) prevailing conditions, such as the proximity of the hazard. This is given by

$$
D(t)=\max _{t^{\prime} \leq t}\left(1+\exp \left[-\mu V\left(t^{\prime}\right)\right]\right)^{-1}
$$

where $D(t)$ is the cumulative share of all people who have evacuated until time instant $t$. This depends on the relative utility to evacuate compared to the alternative of postponing the decision, denoted by $V(t)$. This relative evacuation utility is typically estimated as a combination of factors determining the attractiveness of evacuating. Examples of possible factors which may influence the decision to evacuate (or not) are socio-demographic characteristics (such as age, gender, household composition), spatio-temporal disaster characteristics (such as wind speed, intensity, distance to hazard), the opportunity to undertake property protection, whether neighbours evacuate, the presence of pets, prior evacuation experiences, and whether an evacuation order is given. For a more complete overview of the many different factors that have been reported to determine the evacuation decision we refer to Carnegie and Deka (2010). Different people perceive these factors differently and assign different importance to these factors. The effect of this variance is modelled by the scale parameter $\mu$ in Eq. 3, where a higher value suggests a smaller variance among people.

Equation 3 maximizes over $t^{\prime} \leq t$ since the cumulative share of evacuees is computed and it is assumed that people do not return once they have decided to evacuate. Therefore, the current share of evacuees equals the share of people who would decide on evacuating given any of the previously prevailing conditions. Or in other words, it equals the maximum share of people who have decided to evacuate in any of the previous time instants given the then prevailing utility to evacuate.

The performance of the repeated binary logit model depends evidently on how accurately the relative evacuation utilities $V(t)$ are estimated. Relative utility functions have been estimated for the case of wildfires (Alsnih et al. 2005) and hurricanes (Fu and Wilmot 2004; Fu et al. 2006) using both stated preference surveys and post-hurricane revealed preference surveys. For the case of wildfire evacuation, Alsnih et al. (2005) selected a number of attributes describing weather and wildfire conditions from literature and a 
pre-study focus group. Surveys were carried out with different combinations of attribute levels. A multinomial logit model and mixed logit model were estimated based on the collected stated choice experiment data identifying a number of statistically significant factors: temperature, wind speed, wind direction, fire type, fire distance, and household specific socio-demographic characteristics. Since the levels of these attributes are timedependent, the evacuation participation behaviour can be predicted dynamically as the wildfire evolves. Remarkably, the parameter for the attribute modelling whether the evacuation route was under threat of being cut off by the fire (originally included in the survey) was found to be statistically not significant. This suggests that in this case the decision to evacuate was made independently from the route choice decision. This would mean that the travel demand and traffic assignment can be modelled independently (sequentially). Follow up research is needed to show whether this holds in more cases.

For the case of hurricane evacuation, Fu and Wilmot (2004) estimated a repeated binary logit model based on evacuation behaviour data for hurricane Andrew. They identified as being statistically significant: the distance to the storm, the forward speed of the hurricane, time-of-day (three periods were introduced using dummy variables: morning, afternoon, and night), the presence of an evacuation order, possibility of flooding, and housing type. Later, Fu et al. (2006) estimated the same model (now also including hurricane wind speed and time-to-landfall) for a dataset from hurricane Floyd in South Carolina and tested the calibrated model on the hurricane Andrew data. The predicted dynamic travel demand proved to be similar to the observed travel demand suggesting the transferability of weights to different sites and hurricane scenarios.

In the travel demand models discussed here where a possible evacuation order is included, the impact of the order is typically modelled by estimating the change in evacuation behaviour (i.e., the increase in departure rate) directly after the evacuation order is given. This may be appropriate when the order to evacuate immediately is given suddenly. However, more complex departure behaviour is likely to occur in case of a staged evacuation where (groups of) travellers receive different designated departure time windows in advance, where these instructed departure time windows follow from an evacuation plan set up to moderate evacuation flows and avoid congestion. For instance, people may consider postponing their preferred departure time in order to comply. In order to model this type of behaviour, Pel et al. (2008) proposes including a dynamic term in the evacuation utility function. This factor could be the time difference with the instructed departure time window, which decreases the relative utility of evacuating early, where earlier time instants are associated with a larger disutility, while it increases the relative utility of evacuating late. The latter is justified since the evacuation decision is modelled as a repeated decision whether to evacuate, thus in order to 'comply' once the departure time window has passed people would have to evacuate belatedly. The compliance to the designated time window is then determined by the corresponding weight in the utility function. This weight most likely depends on both the traveller's willingness to comply as well as the level of enforcement conveyed by the authority executing the evacuation plan. For example, instructions distributed through the media may lead to lower compliance than instructions given directly by the police going door-to-door.

\section{Discussion}

The sequential and simultaneous approaches of predicting the evacuation participation rate and departure time profile are both used. Generally speaking, the simultaneous approach applying the repeated binary logit model is typically used in evacuation research focusing 
on predicting the dynamic travel demand under various evacuation conditions. As also mentioned earlier, this might be due to the fact that it provides insight into the actual decisions of evacuees. The sequential approach with a fixed participation rate and exogenous response curve is typically used in practice (including the traffic models used in evacuation studies discussed in "Past and current evacuation traffic simulation models" section), and evacuation research focusing on other aspects than departure time choice behaviour (e.g., with a focus on traffic management). As mentioned earlier, this might be due to its simplicity. The sequential approach using logistical regression or a neural network to predict travel demand has the drawbacks of both approaches. These methods are both not simple in the sense that they require elaborate and specific data, as well as do not provide as much insight into the traveller behaviour as the simultaneous approach. Using neural networks here in particular seems of little value since these models are not generalisable.

The sequential approach as modelled by PBS\&J (2000a) using a cross-classification model was compared with the repeated binary logit model by Fu and Wilmot (2007). As expected, the binary logit model more closely models observed dynamic travel demand behaviour (based on a data set containing evacuation behaviour in southwest Louisiana for hurricane Andrew). The reason why this is expected is that the repeated binary logit model has more flexibility (a higher number of parameters). Hence it is better capable of modelling evacuation behaviour given that elaborate and specific data is available for calibration. In other words, it better allows incorporating all insights on evacuation decision making from the behavioural sciences and empirical studies discussed in "Traveller behaviour under evacuation conditions" section. We would like to emphasize a number of clear behavioural advantages to this approach pointed out by Fu and Wilmot (2007): the model estimates how people dynamically respond to changing hazard conditions, road network conditions, and evacuation instructions, the model provides insight into the observed evacuation behaviour, and the results (weight ratios) appear to be up to a certain level transferable to other sites and situations. Whether the latter advantage can be generalized needs to be shown by future research. In sum, the repeated binary logit model provides insight into trade-offs made in the decision to evacuate, resulting in travel demands that on an aggregated level are more or less consistent with the observed choices. Thereby, given that it is well calibrated, it yields exactly the information that we need as model input for our evacuation traffic simulation models.

A note can be made here on future research on the repeated binary logit model. Current practice is to use the prevailing conditions to estimate the dynamic differential utility to evacuate (compared to not evacuating), as discussed earlier. There is good reason to believe that people not only consider current conditions, but base their decision on the predicted conditions. That is, they also distinguish patterns in changing hazard conditions, such as an increase in wind speed, a rising water level, a growing levee breach and resulting increase in flooding speed, and an increasing wildfire intensity. Similarly, people may distinguish steady conditions from temporary fluctuations, for instance, a wind continuously pushing the wildfire towards the individual or household is perceived differently than a temporary change in wind direction (though having the same instantaneously prevailing conditions). Hence, it might prove worthwhile to estimate these models not on the dynamic prevailing conditions at the time instant that the decision is made, but on the dynamic predicted conditions. As a proxy for these predicted conditions, the recently-past conditions that lead up to the time instant that the decision is made could be used. Clearly, future research needs to show the possible benefit (regarding enhanced predictive power) of this approach. 
To conclude, travel demand is typically predicted as the whole of single trips from origin (often home or work location) to destination (either network exit point or final refuge location). A number of empirical studies support the view that households evacuate as a unit (e.g., Heath et al. 2001; Sime 1993; Zelinsky and Kosinski 1991). Hence, it is implicitly assumed that evacuees belonging to a single household are either already all together upon evacuation or evacuate independently and meet up after arriving outside the threatened region. This is relaxed in work by Murray-Tuite and Mahmassani (2003, 2004). They propose an evacuation model formulation accounting for trip chains due to household interactions. It is simulated how the carless household members are picked up by the other household member(s) at their school, work or residential location to then continue their trip together. Incorporating this household trip chaining principally allows capturing otherwise unexplained evacuation travel patterns (such as longer trips and initially 'evacuating' towards the disaster area) and avoids too optimistic evacuation time predictions. Meeting locations are currently arranged before evacuation, as well as are the carless household members assigned to drivers. The authors point out that further research may consider the impact of communication and traffic information provision on drivers switching pick-ups and rerouting en-route, thus leading to a more efficient evacuation.

\section{Trip distribution modelling}

Trip distribution describes the result of individuals' destination choice. Much fewer studies are conducted on this choice behaviour than on the previously discussed participation and departure time choice behaviour. Also, these studies all share a common approach. Generally speaking, this approach consists of two steps. The factors determining the type of location that people evacuate to are identified first. Second, a (often gravity-based) trip distribution model is used to relate these location type preferences to actual destination choice. Each of these steps is discussed next.

Factors determining type of evacuation location

A small number of studies identify the factors which determine the type of location people evacuate to. This is done using both stated preference and revealed preference data. For instance, Whitehead et al. (2000) and Brodie et al. (2006) report that people with higher income and education tend to evacuate towards hotels and motels, while people with lower income and education tend to evacuate to shelters, based on post-hurricane evacuation data. Deka and Carnegie (2010) build on this by conducting a stated preference survey relating socio-economic and demographic characteristics to the decision whether to evacuate to a shelter location or to a non-shelter location, such as friends or relatives and a hotel or motel. The estimated binary logit model supports similar findings. The probability that a household evacuates to friends or relatives is modelled by Cuellar et al. (2009) in their model for the US Golf coast by the likelihood that the household belongs to the "region's dominant racial group". Whether this can be generalized to other settings can be questioned.

\section{Destination choice modelling}

The US Army Corps of Engineers (1995), in a guideline for hurricane evacuation studies, suggests that evacuees can be allocated to destinations proportionally to the population in 
this possible destination, weighted by a function of the travel distance. This is essentially the gravity-based trip distribution model which is applied to predict the origin-destination matrices used as model input in all the traffic simulation models introduced in "Past and current evacuation traffic simulation models" section.

In other studies, the different location types and accompanying different determining factors as identified by Whitehead et al. (2000) and Brodie et al. (2006) are recognized. For instance, Cuellar et al. (2009) compute attraction potentials per type of location. The attraction for hotels and motels is estimated based on the accommodation availability and a presumed average occupancy rate. Whereas the attraction for shelters is estimated based on the presence of schools with gymnasia where these shelters are often constructed. Location type specific trip potentials and trip attractions are then computed and used in the location type specific gravity-based trip distribution models to predict travellers' destination choice.

Similarly, Cheng (2007) used post-hurricane survey data to estimate a 'friend/relative trip distribution model' and a 'hotel/motel trip distribution model'. In this case, the observed origin-destination matrix was reconstructed based on the survey data and the trip distribution models were estimated to produce the best fitting estimated origin-destination matrix. The gravity-based trip distribution models were calibrated assuming that trip frequencies are considered inversely proportional to the travel distance once outside the threatened zone. Testing the trip length distribution as predicted by the calibrated trip distribution models against observed trip length distributions gave good statistical results. However, little behavioural inferences can be made from such an approach. Therefore, in a later study (Cheng et al. 2008) the same data was used to estimate two multinomial logit models. For the friend/relative model, it was found that, as expected, the parameters for travel distance and the probability that the destination was at risk by the hurricane were negative, indicating that a destination at larger distance and higher risk is less likely to be chosen. Factors having a positive influence on the destination choice of travellers were the destination population, whether the destination is a metropolitan area, and the "percentage of white population" at the destination. For the hotel/motel multinomial logit model the factors travel distance, risk indicator, and white population percentage were also found, with the same effect. Here, also the number of hotels at the destination and the proximity to the interstate motorway had a positive effect. The static approach in this study is relaxed in a subsequent study by Cheng and Wilmot (2009) where time-dependent travel times are included in a quasi-dynamic destination choice model. However, it should be remarked that these time-dependent travel times were reconstructed using the TransCAD traffic simulation model which computes a quasi-dynamic user equilibrium assignment based on link travel times following the Bureau of Public Roads (BPR) function. The authors themselves point out that this approach likely leads to wrong estimates on the prevailing travel times, and suggest improving the destination choice model by applying a different dynamic traffic assignment model.

\section{Discussion}

The available research on evacuation destination choice behaviour shows consistent findings on distinguishing determining factors for destination choice depending on the type of location people evacuate to. Also, it suggests that gravity-based trip distribution models can be used to reconstruct evacuees' destination decisions. However, given that the number of studies is limited and a number of these rely on the same data set, it remains unclear whether these findings can be generalized. More research is needed to show whether this is the case. Future research on evacuation trip distribution modelling should preferably be 
focused on a dynamic approach as this allows capturing the time-dependent destination availability, prevailing travel times, and prevailing risk threat to the destinations (Cheng et al. 2008).

Less focus is laid on travellers' destination choice by, for example, Pel et al. (2008) and Peeta and Hsu (2009). In these traffic simulation models particularly used in short or no notice evacuation it is assumed that travellers do not choose their destination upon departure, but instead tend to choose the route which leads them out of the threatened region as soon as possible. Once safe, they continue their trip to their final destination. This and other route choice models are discussed next.

\section{Traffic assignment modelling}

Traffic assignment relates to assigning travellers to routes, thereby modelling travellers' route choice decisions. A number of studies report on computing evacuation time estimates without the use of traffic assignment as defined here (e.g., Lindell and Prater 2007; Van Zuilekom et al. 2005). These methods sidestep route choice behaviour by simply looking at the total spatially distributed travel demand, the available network exit points, and the capacity bottlenecks in the road network. The ratio of the travel demand (in number of travellers) and network supply (in number of travellers that can pass per unit of time), together with some correction terms, then may give a quick prediction on the minimum time required for the complete evacuation. However, this approach certainly does not provide full insight into the actual evacuation times of regions and neighbourhoods, nor the dynamic evacuation traffic conditions, nor the determining factors underlying the evacuation process. Therefore, we will not discuss this type of models, since this article focuses on traveller behaviour in evacuation traffic simulation models (and the fact that these models are usually applied to gain insight into the determinants of the success or failure of an evacuation and how these can be manipulated).

We structure the following discussion on route choice models by distinguishing models that assume route decisions to occur pre-trip ("Pre-trip route choice models" section), enroute ("En-route route choice models" section), and those combining pre-trip and en-route route decisions ("Hybrid route choice models" section). The user equilibrium assignment assumption applied in most of the traffic simulation models discussed in "Past and current evacuation traffic simulation models" section falls under the pre-trip route choice models discussed next.

Pre-trip route choice models

Within pre-trip route choice models, travellers are assumed to choose their route from origin to destination upon departure (thus termed pre-trip) and do not switch routes while travelling. These routes are chosen based on the currently prevailing or expected route utilities. The chosen routes may prove to be not the most attractive routes when the resulting traffic conditions (derived after simulation) deviate from the initially predicted traffic conditions on which the route choices were based. Therefore, typically an iterative procedure is used that allows travellers to choose a different route in the next iteration, based on the actually experienced route costs. Repeating this process over a sufficiently large number of iterations leads to a user equilibrium assignment in which no traveller can unilaterally switch routes and be better off (Wardrop's equilibrium law, see Wardrop 1952). 
In simulating pre-trip route choice, route flow fractions are computed at the origins and travellers are propagated from origins to destinations along these routes. The route flow fractions are determined by the probabilities that each route has the highest route utility, where these expected route utilities more closely resemble the actual (observed) route utilities as the number of iterations increases. These pre-trip route choice models within an equilibrium framework are generally used for many dynamic traffic assignment applications, though mainly for long-term planning purposes where it can be assumed that travellers have past experiences leading to well-informed expectations about the future traffic conditions that they will encounter during their trip. This assumption on travellers' learning and habit formation is most likely not an appropriate assumption for the case of evacuation route choice behaviour. The reason for this is that evacuation is a low-frequent exceptional event accompanied by an unusual travel demand pattern and unusual network capacity (due to the combination of different driving behaviour, dynamic traffic control measures, and the adverse disaster conditions) resulting in different-from-normal traffic conditions, which are difficult to anticipate on.

The pre-trip route choice model in an equilibrium framework is applied in most of the dynamic traffic simulation models discussed in "Past and current evacuation traffic simulation models" section, as well as in a number of other evacuation studies (e.g., Goemans and Jansen 2009; Lin et al. 2009; Song et al. 2009).

An approach which is equivalent to an iterative user equilibrium assignment is by applying an incremental assignment method adopted by, for instance, Brown et al. (2009) while developing a hurricane evacuation model. Here, (pre-trip) route choices are modelled sequentially, instead of iteratively. Travellers are assigned to a route in a step-wise fashion. In one step, the (predicted) route costs are computed and a small number of travellers are assigned to the then most attractive routes. In the next step, the route costs are updated based on the new route flows, and again a small number of travellers are assigned to the most attractive routes. When the increments (i.e., the number of travellers assigned to a new route in each step) are sufficiently small, then a user equilibrium assignment is reached once all steps are executed and all travellers have been assigned to a route. Therefore, the same (likely inappropriate) behavioural assumption is made as with the iterative procedure computing the user equilibrium assignment.

In some of the traffic simulation models discussed in "Past and current evacuation traffic simulation models" section (OREMS, MASSVAC, VISSIM, INDY) user-defined routes and route flow fractions can be model input. This allows evaluating (mandatory) instructions regarding prescribed evacuation routes. These prescribed evacuation routes do not necessarily minimize individual travel costs, thus leading to a user equilibrium, but may instead aim at minimizing, for instance, the total travel costs, thus leading to a system optimum (simulated by, e.g., Li et al. 2006; Liu et al. 2007; Kalafatas and Peeta 2009; Zheng et al. 2010). Other optimization objectives than the system optimum have been used. An overview can be found in Yuan and Han (2009) and Huibregtse et al. (2010). The important issue here is that testing evacuation route instructions while simulating pre-trip route choice disables incorporating (partial) traveller compliance behaviour. It is necessarily assumed that travellers fully comply, since the pre-trip route choice model does not allow travellers to deviate from their (prescribed) evacuation route during their trip. The discussion in "Traveller behaviour under evacuation conditions" section shows that this full compliance assumption is most certainly too strict. 
En-route route choice models

The assumption that travellers cannot deviate from their (pre-trip) chosen route is relaxed in case of en-route route choice. Here, travellers observe prevailing traffic conditions as they travel, and make route choice decisions accordingly. En-route route choice models thus simulate travellers who travel from one intersection to the next, every time deciding on the next downstream direction based on route guidance or the available information on the prevailing (instantaneous or predicted) traffic conditions.

In simulating en-route route choice, link flow fractions (also called split proportions or turn fractions) are computed at all intersection nodes, and travellers are propagated from one intersection node to the next along the downstream links. The link flow fraction for a downstream link is computed by the probability that any route (starting at the intersection node) in this downstream direction has the lowest route costs. This myopic opportunistic travel behaviour is described by, for instance, a set of fuzzy rules (Peeta and Yu 2005), recurrent neural network (Yang et al. 1995), fuzzy network (Hawas 2004), or discrete probabilistic choice model (Dia et al. 2001; Adler et al. 1993). This approach has been mainly applied in dynamic traffic assignment applications on the impact of route guidance or traffic information. Evacuation studies using the en-route route choice model are scarce. One possible example is the study by Mitchell and Radwan (2006) using INTEGRATION (Rakha and van Aerde 2004) to study the impact of evacuation staging on network clearance time. However, it should be mentioned that INTEGRATION provides both pretrip and en-route route choice models and it is not fully clear which route choice model alternative was used in this study.

\section{Hybrid route choice models}

The assumption that travellers fully rely on past experiences in their route decisions (as made in pre-trip route choice models), as well as the assumption that travellers base their route decisions solely on prevailing traffic conditions (as made in en-route route choice models), are both relaxed in the hybrid route choice models. The hybrid models incorporate the impact of unfamiliarity with traffic conditions and the provision of en-route traffic information by combining pre-trip route choice with en-route route switching. Travellers are assumed to choose an initial route upon departure, after which they may adapt their route during their trip. They might do so when prevailing traffic conditions are such that travellers are better off (or have the feeling of being better off) by deviating to another route. A hybrid route choice model is used in DYNASMART (Mahmassani 2001) and EVAQ (Pel et al. 2009, 2011). The main difference is that in the mesoscopic DYNASMART model the route switching is checked for each individual traveller, while in the macroscopic EVAQ model this is checked for each intersection node and each class of travellers having the same initial route.

In the macroscopic hybrid route choice model used in EVAQ, travellers who initially follow the same (pre-trip) route are said to belong to the same class. The class-specific route flow fractions are computed at all intersection nodes, and travellers of all classes are propagated along these routes until some travellers decide to switch to an alternative route. The route flow fractions for travellers of a specific class (i.e., initially following the same route) switching to an alternative route is given by the probability that this alternative route has the lowest route costs.

Note that the pre-trip route choice model and en-route route choice model are special cases of the hybrid route choice model. In both of the hybrid route choice models 
mentioned above, travellers only consider switching routes when the alternative route provides some minimum improvement. In the special case when this minimum improvement is set to infinite, travellers never deviate from their pre-trip chosen route (thus modelling pre-trip route choice). Whereas in the special case when this minimum improvement is set to zero, travellers always choose the then most attractive route, independent of their initial pre-trip chosen route (thus modelling en-route route choice). Values for the minimum improvement between zero and infinite allow modelling intermediate states where travellers make a trade-off between continuing on the pre-trip chosen route and diverting to a more attractive route.

Hybrid route choice models allow modelling and evaluating evacuation route instructions, while accounting for partial traveller compliance. In this case, the initial (pre-trip chosen) routes can be set as the prescribed evacuation routes. Hence, the minimum improvement for travellers to deviate from their route represents the level of travellers' compliance, where a higher minimum improvement leads to a higher compliance level (since this reduces the probability of a more attractive alternative route), and vice versa. This way, the hybrid route choice model formulation in EVAQ has been exploited by Pel et al. (2010a) to evaluate the impact of partial traveller compliance on existing evacuation traffic plans, and by Pel et al. (2010c) to design new optimal evacuation plans while anticipating partial traveller compliance behaviour.

\section{Discussion}

Pre-trip route choice is implemented in many traffic simulation models including most of those used in evacuation studies reported in "Past and current evacuation traffic simulation models" section. That the underlying behavioural assumption that travellers have wellinformed expectations about the future traffic conditions that they will encounter during their trip (possibly from past experiences) is inappropriate, is supported by the discussion in "Traveller behaviour under evacuation conditions" section as well as a number of empirical studies. These empirical studies show the large role of rerouting behaviour, thus favouring the en-route and hybrid route choice models. For instance, Knoop et al. (2010) analyse how travellers use the provided traffic information when faced with otherwise unfamiliar traffic conditions (in this case not evacuation, but the aftermath of large scale traffic accidents). They found that a large share of travellers (up to 50\%) is inclined to switch routes based on the prevailing traffic information. Also, rerouting is much more often observed when the origin of the adverse traffic conditions is an uncommon event (in this case the major traffic accident), as compared to equal adverse traffic conditions due to a recurring event (e.g., day-to-day fluctuations in travel demand and network capacity). Similar conclusions were drawn by Robinson and Khattak (2010) using stated choice preference surveys on route choice under hypothetical evacuation situations. They observed that a large share of respondents (up to 72\%) anticipated rerouting in case of evacuation, regardless of whether or not they frequently altered routes under non-evacuation conditions to avoid congestion. This rerouting behaviour can only be simulated using en-route or hybrid route choice models.

En-route and hybrid route choice models have another related advantage over pre-trip route choice models. Namely, the ability to model real-time traveller responses to changes in the road network conditions due to the hazard's evolution in space and time (e.g., road sections becoming inaccessible due to flooding) and dynamic traffic regulations and control measures (e.g., contraflow operations to increase outbound capacity). The effect of these road infrastructure dynamics can only be properly modelled by en-route and hybrid route 
choice models. This is due to the fact that in models with pre-trip route choice there is no way to avoid travellers from following the chosen route, even if the next link is obviously inaccessible. Therefore, the possibility of inaccessible road sections due to network fall-out prohibits pre-trip route choice and requires en-route route decisions once travellers become aware of the changes in network conditions. Consequently, travellers will take detours around prevailing inaccessible sections of the road network.

Finally, when testing and evaluating optimal evacuation routes, hybrid route choice models allow simulating partial traveller compliance behaviour, which is most likely to occur, as argued in "Traveller behaviour under evacuation conditions" section. By varying the minimum improvement that travellers require before deviating from their dedicated evacuation route, insight can be gained into the impact of evacuation instructions under various traveller compliance levels. This enables both testing the robustness of existing evacuation plans towards uncertain traveller compliance levels, as well as designing evacuation plans while anticipating the expected traveller compliance behaviour.

In sum, hybrid route choice models are the most flexible and likely also the most appropriate approach in modelling travellers' route choice behaviour during evacuation, as these allow incorporating the impact of dynamic traffic information, changes in the road network conditions, and partial traveller compliance behaviour towards evacuation route instructions. That these factors play an important role in evacuation studies is shown by the discussion in "Traveller behaviour under evacuation conditions" section.

A final note can be made here on the fact that simulated route choice decisions are often determined by (expected) (prevailing) route travel times. The generalized route costs can arguably be appended with other attributes playing a role in travellers' route decisions. For instance, Chiu and Mirchandani (2008) argue that there is a bias towards using familiar routes and motorways, where the latter might be ascribed to the perception of these roads being more reliable. This is supported by the studies by Dow and Cutter (2002) and Lindell and Prater (2006) reporting high traffic volumes on the interstate motorways in the evacuations preceding respectively hurricane Floyd and hurricane Katrina despite the availability of alternative routes using rural roads. Further research is needed to show the actual role that these and similar route attributes play in evacuation route decisions.

\section{Concluding comments}

The content and contribution of this article is twofold. First of all, it structures the current state-of-the-practice in evacuation traffic simulation studies. To this end, a perspective is given on past and present evacuation traffic simulation models, and the current consensus on evacuation travel behaviour. The latter based on psycho-behavioural constructs from the social sciences and empirical studies on evacuation behaviour. We argued that people do not automatically follow the advice and orders from public officials, but tend to seek information, assess their personal risk, and make independent evacuation decisions. It is therefore essential that dynamic traffic simulation models that aim to simulate an evacuation simulate this reactive traveller behaviour, therewith incorporating the important role of time-varying disaster conditions, (traffic) information, and warnings, discretionary advice and evacuation orders. From this viewpoint, the different model formulations to simulate travel behaviour were elaborated on, as well as their suitability to the case of evacuation. For the evacuation participation and departure time choice we argued in favour of the simultaneous approach to dynamic evacuation demand prediction using the repeated binary logit model. The repeated binary logit model provides insight into trade-offs made 
in the decision to evacuate, resulting in dynamic travel demands that on an aggregated level are more or less consistent with the observed choices. For the destination choice we showed how future research is needed to generalize the current preliminary findings on the location-specific (gravity-based) destination choice models. For the evacuation route choice we argued in favour of the use of a hybrid route choice model. This since hybrid route choice models allow incorporating the impact of dynamic traffic information, changes in the road network conditions, and partial traveller compliance behaviour towards evacuation route instructions.

Second of all, this article gives direction to the current state-of-the-art in modelling evacuation travel behaviour. This is done by reviewing and consolidating the past and current research efforts on different model formulations describing the evacuation choice, departure time choice, destination choice, and route choice. Within each of these discussions, we pointed at current limitations and made corresponding suggestions on promising future research directions.

Open Access This article is distributed under the terms of the Creative Commons Attribution Noncommercial License which permits any noncommercial use, distribution, and reproduction in any medium, provided the original author(s) and source are credited.

\section{References}

Abdelgawad, H., Abdulhai, B.: Emergency evacuation planning as a network design problem: a critical review. Transp. Lett. 1(1), 41-58 (2009)

Adler, J.L., Recker, W.W., McNally, M.G.: A conflict model and interactive simulator (FASTCARS) for predicting en-route driver behaviour in response to real-time traffic condition information. Transportation 20(2), 83-106 (1993)

Aguirre, B.E.: Commentary on understanding mass panic and other collective responses to threat and disaster: emergency evacuations, panic, and social psychology. Psychiatry 68, 121-129 (2005)

Alsnih, R., Rose, J., Stopher, P.: Understanding household evacuation decisions using a stated choice survey - case study of bush fires. In: Proceedings of the 84th Annual Meeting Transportation Research Board, Washington, DC, USA (2005)

Baddeley, A.D.: Selective attention and performance in dangerous environments. Br. J. Psychol. 63, 537-546 (1972)

Baker, E.J.: Hurricane evacuation behavior. Int. J. Mass Emerg. Disasters 9(2), 287-310 (1991)

Baker, E.J.: Public responses to hurricane probability forecasts. Prof. Geogr. 47(2), 137-147 (1995)

Balakrishna, R., Wen, Y., Ben-Akiva, M., Antoniou, C.: Simulation-based framework for transportation network management for emergencies. Transp. Res. Rec. 2041, 80-88 (2008)

Barrett, B., Ran, B., Pillai, R.: Developing a dynamic traffic management modelling framework for hurricane evacuation. Transp. Res. Rec. 1733, 115-121 (2000)

Blake, S.J., Galea, E.R., Westeng, H., Dixon, A.J.P.: An analysis of human behavior during the WTC disaster of 11 September 2001 based on published survivor accounts. In: Proceedings of the Third International Symposium on Human Behavior in Fire, pp. 181-192. InterScience Communications, London (2004)

Bohannon, J.: Directing the herd: crowds and the science of evacuation. Science 310, 219-221 (2005)

Brodie, M., Weltzien, E., Altman, D.: Experiences of hurricane Katrina evacuees in Houston shelters: implications for future planning. Am. J. Public Health 96, 1402-1408 (2006)

Brown, C., White, W., van Slyke, C., Benson, J.D.: Development of a strategic hurricane evacuation dynamic traffic assignment model for the Houston region. In: Proceedings of the 88th Annual Meeting Transportation Research Board, Washington, DC, USA (2009)

Carnegie, J.A., Deka, D.: Using hypothetical disaster scenarios to predict evacuation behavioral response. In: Proceedings of the 89th Annual Meeting of the Transportation Research Board, Washington, DC, USA (2010)

Chen, X., Zhan, F.B.: Agent-based modeling and simulation of urban evacuation: relative effectiveness of simultaneous and staged evacuation strategies. In: Proceedings of the 83rd Annual Meeting Transportation Research Board, Washington, DC, USA (2004) 
Cheng, G.: Friction factor functions calibration for hurricane evacuation trip distribution. In: Proceedings of the 86th Annual Meeting Transportation Research Board, Washington, DC, USA (2007)

Cheng, G., Wilmot, C.G.: Investigate time-dependent travel cost impact on hurricane evacuation destination choice models. In: Proceedings of the 88th Annual Meeting Transportation Research Board, Washington, DC, USA (2009)

Cheng, G., Wilmot, C.G., Baker, E.J.: A destination choice model for hurricane evacuation. In: Proceedings of the 87th Annual Meeting Transportation Research Board, Washington, DC, USA (2008)

Chiu, Y.C., Mirchandani, P.B.: Online behavior-robust feedback information routing strategy for mass evacuation. IEEE Trans. Intell. Transp. Syst. 9(2), 264-274 (2008)

Chiu, Y., Villalobos, J., Gautam, B., Zheng, H.: Modeling and solving the optimal evacuation-route-flowstaging problem for no-notice extreme events. In: Proceedings of the 85th Annual Meeting Transportation Research Board, Washington, DC, USA (2006)

Cornwell, B.: Bonded fatalities: relational and ecological dimensions of a fire evacuation. Sociol. Q 44, 617-638 (2003)

Court, M., Pittman, J., Alexopoulos, C., Goldsman, D., Kim, S., Loper, M., Pritchett, A., Haddock, J.: A framework for simulating human cognitive behavior and movement when predicting impacts of catastrophic events. In: 2004 Winter Simulation Conference (2004)

Cova, T.J., Johnson, J.P.: Microsimulation of neighborhood evacuations in the urban-wildlife interface. Environ. Plan. A 34(12), 2211-2229 (2002)

Cova, T.J., Johnson, J.P.: A network flow model for lane-based evacuation routing. Transp. Res. A 37(7), 579-604 (2003)

Cuellar, L., Kubicek, D., Hengartner, N., Hansson, A.: Emergency relocation: population response model to disasters. In: Proceedings of the IEEE Conference on Technologies for Homeland Security, Boston, MA, USA, pp. 628-635 (2009)

Dash, N., Gladwin, H.: Evacuation decision making and behavioral responses: individual and household. Nat. Hazards Rev. 8(3), 69-77 (2007)

Dash, N., Morrow, B.H.: Return delays and evacuation order compliance: the case of hurricane Georges and the Florida Keys. Environ. Hazards 2, 119-128 (2001)

De Jong, M., Helsloot, I.: The effects of information and evacuation plans on civilian response during the national Dutch crisis exercise 'Waterproef'. In: Hoogendoorn, S.P., Pel, A.J., Taylor, M.A.P., Mahmassani, H. (eds.) Proceedings of the 1st International Conference on Evacuation Modeling and Management, pp. 153-162. Elsevier, Amsterdam (2010)

Deka, D., Carnegie, J.A.: Analyzing evacuation behavior of transportation-disadvantaged populations in northern New Jersey. In: Proceedings of the 89th Annual Meeting of the Transportation Research Board, Washington, DC, USA (2010)

Dia, H., Harney, D., Boyle, A.: Dynamics of drivers' route choice decisions under advanced traveller information systems. Road Transp. Res. 10, 2-12 (2001)

Dombroski, M., Fischhoff, B., Fischbeck, P.: Predicting emergency evacuation and sheltering behavior: a structured analytical approach. Risk Anal. 26(6), 1675-1688 (2006)

Dow, K., Cutter, S.L.: Crying wolf: repeat responses to hurricane evacuation orders. Coast. Manag. 26, 237-252 (1998)

Dow, K., Cutter, S.L.: Public orders and personal opinions: household strategies for hurricane risk assessment. Environ. Hazards 2, 143-155 (2000)

Dow, K., Cutter, S.L.: Emerging hurricane evacuation issues: Hurricane Floyd and South Carolina. Nat. Hazards Rev. 3(1), 12-18 (2002)

Durham, C.M.: Hurricane evacuation. In: Proceedings of the 86th Annual Meeting Transportation Research Board, Washington, DC, USA (2007)

Franzese, O., Han, L.D.: Traffic modeling framework for hurricane evacuation. Internal report, Oak Ridge National Laboratory, Oak Ridge (2001)

Fu, H.: Development of dynamic travel demand models for hurricane evacuation. Dissertation, Louisiana State University, USA (2004)

Fu, H., Wilmot, C.G.: A sequential logit dynamic travel demand model for hurricane evacuation. Transp. Res. Rec. 1882, 19-26 (2004)

Fu, H., Wilmot, C.G.: Static vs. dynamic and aggregate vs. disaggregate: a comparison between practice and research in hurricane evacuation travel demand modeling. In: Proceedings of the 86th Annual Meeting Transportation Research Board, Washington, DC, USA (2007)

Fu, H., Wilmot, C.G., Zhang, H.: Modeling the hurricane evacuation response curve. Transp. Res. Rec. 2022, 94-102 (2006)

Glass, A.: Psychological aspects of disaster. JAMA 171(2), 222-225 (1959) 
Goemans, J.W., Jansen, W.R.: Development and applications of a GIS-based traffic evacuation model for Haaglanden, the Netherlands, using the 'Hoogwater? Vrije weg!' toolbox. In: Proceedings of the 1st International Conference on Evacuation Modeling and Management, The Hague, The Netherlands (2009)

Goldblatt, R.B.: Evacuation planning, human factors and traffic engineering perspectives. In: Proceedings of the 2004 European Transport Conference, Strasbourg, France (2004)

Han, L.D., Yuan, F.: Evacuation modeling and operations using dynamic traffic assignment and most desirable destination approaches. In: Proceedings of the 84th Annual Meeting Transportation Research Board, Washington, DC, USA (2005)

Hardy, M., Wunderlich, K., Bunch, J., Smith, T.: Structuring modeling and simulation analyses for evacuation planning and operations. In: Proceedings of the 89th Annual Meeting of the Transportation Research Board, Washington, DC, USA (2010)

Hawas, Y.E.: Development and calibration of route choice utility models: neuro-fuzzy approach. J. Transp. Eng. 130(2), 171-182 (2004)

Heath, S.E., Kass, P.H., Beck, A.M., Glickman, L.T.: Human and pet-related risk factors for household evacuation failure during a natural disaster. Am. J. Epidemiol. 153(7), 659-665 (2001)

Henson, K.M., Goulias, K.G., Golledge, R.G.: An assessment of activity-based modelling and simulation for applications in operational studies, disaster preparedness, and homeland security. Transp. Lett. 1(1), 19-39 (2009)

Hobeika, A.G., Jamei, B.: MASSVAC: a model for calculating evacuation times under natural disaster. In: Proceedings of the Computer Simulation in Emergency Planning Conference, La Jolla, USA (1985)

Hobeika, A.G., Kim, C.: Comparison of traffic assignments in evacuation modeling. IEEE Trans. Eng. Manag. 45(2), 192-198 (1998)

Hoogendoorn, R.G.: State-of-the-art driving theory and modeling in case of adverse conditions. Internal report, Delft University of Technology, Delft (2010)

Hoogendoorn, S.P., Knoop, V., Pel, A.J., Huibregtse, O.L., Hoogendoorn, R., Landman, R.: Verkeersmanagement bij exceptionele omstandigheden [Dutch: Traffic management for exceptional conditions]. N. M. Mag. 2, 25-28 (2009)

Hooke, W.H.: US participation in international decade for natural disaster reduction. Nat. Hazards Rev. 1, 2-9 (2000)

Huibregtse, O.L., Hoogendoorn, S.P., Bliemer, M.C.J.: Optimization of evacuation measures under uncertainty. In: Proceedings of the 89th Annual Meeting of the Transportation Research Board, Washington, DC, USA (2010)

Jonkman, S.N.: Loss of life estimation in flood risk assessment: theory and applications. Dissertation, Delft University of Technology, The Netherlands (2007)

Kalafatas, G., Peeta, S.: Planning for evacuation: insights from an efficient network design model. J. Infrastruct. Syst. 15(1), 21-30 (2009)

KLD: Formulations of the DYNEV and I-DYNEV traffic simulation models used in ESF. Technical report prepared for the Federal Emergency Management Agency, KLD Associates, Washington, DC (1984)

Klunder, G., Terbruggen, S., Mak, J., Immers, B.: Large-scale evacuation of the Randstand: evacuation simulations with the dynamic traffic assignment model Indy. In: Proceedings of the 1st International Conference on Evacuation Modeling and Management, The Hague, The Netherlands (2009)

Knoop, V.L., Hoogendoorn, S.P., Van Zuylen, H.J.: Rerouting behaviour of travellers under exceptional traffic conditions - an empirical analysis of route choice. In: Hoogendoorn, S.P., Pel, A.J., Taylor, M.A.P., Mahmassani, H. (eds.) Proceedings of the 1st International Conference on Evacuation Modeling and Management, pp. 113-128. Elsevier, Amsterdam (2010)

Knowles, L.: Sydney bushfire emergency evacuation: analysis of qualitative research conducted with home owners in bushfire-prone areas. Internal Report. Institute of Transport Studies, University of Sydney (2003)

Lave, B.L., Apt, J.: Planning for natural disasters in a stochastic world. J. Risk Uncertain. 33, 117-130 (2006)

Lave, B.L., Resendiz-Carrilla, D., McMichael, F.: Safety goals for high-hazard dams: are dams too safe? Water Resour. Res. 26, 1683-1691 (1990)

Leach, J., Campling, J.: Survival Psychology. Palgrave Macmillan, Basingstoke (1982)

Lewis, D.: September's great escape: new information system helps manage hurricane evacuations. Roads Bridges 39, 40-42 (2001)

Li, Q., Yang, X., Wei, H.: Integrating traffic simulation models with evacuation planning system in a GIS environment. In: Proceedings of the IEEE Intelligence Transportation Systems Conference, Toronto, Canada (2006)

Lin, D.Y., Eluru, N., Waller, S.T., Bhat, C.R.: Evacuation planning using the integrated system of activitybased modeling and dynamic traffic assignment. Transp. Res. Rec. 2132, 69-77 (2009) 
Lindell, M.K.: EMBLEM2: an empirically based large scale evacuation time estimate model. Transp. Res. A 42, 14-154 (2008)

Lindell, M.K., Prater, C.S.: Evacuation from hurricane Katrina: Jefferson and St. Charles parishes. In: Proceedings of the National Hurricane Conference, Orlando, FL, USA (2006)

Lindell, M.K., Prater, C.S.: Critical behavioral assumptions in evacuation time estimate analysis for private vehicles: examples from hurricane research and planning. J Urban Plan. Dev. 133(1), 18-29 (2007)

Lindell, M.K., Lu, J.C., Prater, C.S.: Household decision making and evacuation in response to hurricane Lili. Nat. Hazards Rev. 6(4), 171-179 (2005)

Liu, Y., Lai, X., Chang, G.: Two-level integrated optimization system for planning of emergency evacuation. J. Transp. Eng. 32(10), 800-807 (2006)

Liu, H.X., He, X., Ban, X.: A cell-based many-to-one dynamic system optimal model and its heuristic solution method for emergency evacuation. In: Proceedings of the 86th Annual Meeting Transportation Research Board, Washington, DC, USA (2007)

Mahmassani, H.S.: Dynamic network traffic assignment and simulation methodology in advanced system management applications. Netw. Spat. Econ. 1, 267-292 (2001)

Mawson, A.R.: Understanding mass panic and other collective responses to threat and disaster. Psychiatry 68, 95-113 (2005)

Mileti, D.S., Drabek, T.E., Haas, E.: Human systems in extreme environments: a sociological perspective. Program on Technology, Environment and Man, Monograph No. 21, Institute of Behavioral Science, University of Colorado, Boulder (1975)

Mitchell, S.W., Radwan, E.: Heuristic prioritization of emergency evacuation staging to reduce clearance time. In: Proceedings of the 85th Annual Meeting Transportation Research Board, Washington, DC, USA (2006)

Murakami, Y., Minami, K., Kawasoe, T., Ishida, T.: Multi-agent simulation for crisis management. In: Proceedings of the IEEE on Knowledge Media Networking Workshop, pp. 135-139 (2002)

Murray-Tuite, P.: Perspectives for network management in response to unplanned disruptions. J Urban Plan. Dev. 133(1), 9-17 (2007)

Murray-Tuite, P., Mahmassani, H.S.: Model of household trip chain sequencing in an emergency evacuation. Transp. Res. Rec. 1831, 21-29 (2003)

Murray-Tuite, P., Mahmassani, H.S.: Transportation network evacuation planning with household activity interactions. Transp. Res. Rec. 1894, 150-159 (2004)

Newkirk, R.T.: The increasing cost of disaster in developed countries: a challenge to local planning and government. J. Conting. Crisis Manag. 9(3), 159-170 (2001)

Noh, H., Chiu, Y.C., Zheng, H., Hickman, M., Mirchandani, P.: An approach to modeling demand and supply for a short-notice evacuation. Transp. Res. Rec. 2091, 91-99 (2009)

ORNL: Responding to energy-related emergencies. Oak Ridge Natl. Lab. Rev. 35(2) (2002). http://www. ornl.gov/info/ornlreview/v35_2_02/responding.shtml

Ozbay, K., Yazici, A.M.: Analysis of network-wide impacts of behavioral response curves for evacuation conditions. In: Proceedings of the IEEE Intelligence Transportation Systems Conference, Toronto, Canada (2006)

PBS\&J: Evacuation travel demand forecasting system. Technical report, PBS\&J Inc, Tallahassee, FL, USA (2000a)

PBS\&J: Southwest Louisiana hurricane evacuation study: transportation model support document. PBS\&J Inc, Tallahassee (2000b)

Peeta, S., Hsu, Y.T.: Behavior modeling for dynamic routing under no-notice mass evacuation. In: Proceedings of the 12th International Conference on Travel Behaviour Research, Jaipur, India (2009)

Peeta, S., Yu, J.W.: A hybrid model for driver route choice incorporating en-route attributes and real-time information effects. Netw. Spat. Econ. 5(1), 21-40 (2005)

Pel, A.J., Bliemer, M.C.J., Hoogendoorn, S.P.: EVAQ: a new analytical model for voluntary and mandatory evacuation strategies on time-varying networks. In: Proceedings of the 11th IEEE Conference on Intelligence Transportation Systems, Beijing, China (2008)

Pel, A.J., Bliemer, M.C.J., Hoogendoorn, S.P.: Hybrid route choice modeling in dynamic traffic assignment. Transp. Res. Rec. 2091, 100-107 (2009)

Pel, A.J., Bliemer, M.C.J., Hoogendoorn, S.P.: Simulating travel behavior under evacuation conditions. Eur. J. Transp. Infrastruc. Res. (under review) (2011)

Pel, A.J., Hoogendoorn, S.P., Bliemer, M.C.J.: Evacuation modeling including traveler information and compliance behavior. In: Hoogendoorn, S.P., Pel, A.J., Taylor, M.A.P., Mahmassani, H. (eds.) Proceedings of the 1st International Conference on Evacuation Modeling and Management, pp. 101-111. Elsevier, Amsterdam (2010a)

Pel, A.J., Hoogendoorn, S.P., Bliemer, M.C.J.: Impact of variations in travel demand and network supply factors for evacuation studies. Transp. Res. Rec. (in press) (2010b) 
Pel, A.J., Huibregtse, O.L., Hoogendoorn, S.P., Bliemer, M.C.J.: Optimizing evacuation instructions while anticipating traveler compliance behavior. In: Proceedings of the 13th IEEE Conference on Intelligence Transportation Systems, Madeira Island, Portugal (2010c)

Pelechano, N., Badler, N.: Modeling crowd and trained leader behavior during building evacuation. IEEE Comput. Graph. Appl. 26(6), 80-86 (2006)

Pelechano, N., O'Brien, K., Silverman, B., Badler, N.: Crowd simulation incorporating agent psychological models, roles and communication. In: Proceedings of the First International Crowd Simulation Workshop (2005)

Pidd, M., de Silva, F.N., Eglese, R.: CEMPS: a configurable evacuation management and planning systema progress report. In: Proceedings of the 1993 Winter Simulation Conference (1993)

Plowman, T.: Danger! Hurricane coming. Planning 67(12), 16-21 (2001)

Quarantelli, E.L.: The behavior of panic participants. Sociol. Soc. Res. 41, 187-194 (1957)

Raggatt, P., Butterworth, E., Morrissey, S.: Issues in natural disaster management: community response to the threat of tropical cyclones in Australia. Disaster Prev. Manag. 2(3), 12-21 (1993)

Rakha, H., van Aerde, M.: INTEGRATION User's Guide, vols. I and II. Van Aerde \& Associates, Kingston (2004)

Rasid, H., Wolfgang, H., Hunt, L.: Post-flood assessment of emergency evacuation policies in the Red River basin, southern Manitoba. Can. Geogr. 44(2), 369-386 (2000)

Rathi, A.K., Solanki, R.S.: Simulation of traffic flow during emergency evacuations: a microcomputer based modeling system. In: Proceedings of the 1993 Winter Simulation Conference (1993)

Robinson, R.M., Khattak, A.: Route change decision-making by hurricane evacuees facing congestion. In: Proceedings of the 89th Annual Meeting of the Transportation Research Board, Washington, DC, USA (2010)

Schadschneider, A., Klingsch, W., Klupfel, H., Kretz, T., Rogsch, C., Seyfried, A.: Evacuation dynamics: empirical results, modeling and applications. In: Meyers, B. (ed.) Encyclopedia of Complexity and Systems Science. Springer, Berlin (2008)

Schmidt, L.J., Warner, B.: PANIC: Origins, Insight and Treatment. North Atlantic Books, Berkley (2002)

Sheffi, Y., Mahmassani, H.S., Powell, W.: NETVAC: A Transportation Network Evacuation Model. Center for Transportation Studies, MIT, Boston (1980)

Shendarkar, A., Vasudevan, K., Lee, S., Son, Y.: Crowd simulation for emergency response using BDI agent based on virtual reality. In: Proceedings of the 2006 Winter Simulation Conference (2006)

Sherali, H.D., Carter, T.B., Hobeika, A.G.: A location-allocation model and algorithm for evacuation planning under hurricane/flood conditions. Transp. Res. B 25(6), 439-452 (1991)

Sime, J.D.: Crowd psychology and engineering: designing for people or ball-bearings? In: Smith, R.A., Dickie, J.F. (eds.) Engineering for Crowd Safety, pp. 119-131. Elsevier, New York (1993)

Song, W., Zhu, L., Li, Q., Wang, X.D., Liu, Y., Dong, Y.C.: Evacuation model and application for emergency events. In: Proceedings of the 4th IEEE International Conference on Computer Science and Information Technology, Seoul, Korea (2009)

Tu, H., Tamminga, G., Drolenga, H., De Wit, J., Van Der Berg, W.: Evacuation plan of the city of Almere: simulating the impact of driving behaviors on evacuation clearance time. In: Hoogendoorn, S.P., Pel, A.J., Taylor, M.A.P., Mahmassani, H. (eds.) Proceedings of the 1st International Conference on Evacuation Modeling and Management, pp. 67-75. Elsevier, Amsterdam (2010)

Tweedie, S., Rowland, J., Walsh, S., Rhoten, R.: A methodology for estimating emergency evacuation times. Soc. Sci. J. 23(2), 189-204 (1986)

Tyhurst, J.: Individual reactions to community disaster: the natural history of psychiatric phenomena. Am. J. Psychiatry 107(10), 764-769 (1951)

US Army Corps of Engineers: Technical guidelines for hurricane evacuation studies. Technical report (1995)

Van Zuilekom, K., van Maarseveen, M., van der Doef, M.: A decision support system for preventive evacuation of people. In: Geo-Information for Disaster Management, pp. 229-253. Springer, Berlin (2005)

Wang, H., Andrews, S., Daiheng, N., Collura, J.: Scenario-based analysis of transportation impacts in case of dam failure flood evacuation in Franklin county, Massachusetts. In: Proceedings of the 89th Annual Meeting of the Transportation Research Board, Washington, DC, USA (2010)

Wardrop, J.G.: Some theoretical aspects of road traffic research. In: Proceedings of the Institution of Civil Engineers II(1) (1952)

Whitehead, J.C., Edwards, B., van Willigen, M., Maiolo, J.R., Wilson, K., Smith, K.T.: Heading for higher ground: factors affecting real and hypothetical hurricane evacuation behaviour. Glob. Environ. Chang. B 2, 133-142 (2000) 
Wickens, C.D.: Attention. In: Hancock, P.A. (ed.) Human Factors Psychology, pp. 29-79. Elsevier Science Publishers B.V., Amsterdam (1987)

Williams, B., Tagliaferri, A., Meinhold, S., Hummer, J., Rouphail, N.: Simulation and analysis of freeway lane reversal for coastal hurricane evacuation. J Urban Plan. Dev. 133(1), 61-72 (2007)

Wills, R.H.: Human Instincts, Everyday Life, and the Brain. Book Emporium, Canada (1998)

Wilmot, C.G., Meduri, N.: A methodology to establish hurricane evacuation zones. Transp. Res. Rec. 1922, 129-137 (2005)

Wilmot, C.G., Mei, B.: Comparison of alternative trip generation models for hurricane evacuation. In: Proceedings of the 82nd Annual Meeting Transportation Research Board, Washington, DC, USA (2003)

Wilmot, C.G., de Lapparent, M., Taylor, M.A.P., Arce, C., Baker, E., Cherrington, L., Gripsrud, M., Lian, J.I., Manore, M., Potier, F.: What data do we need for the management (and modelling) of emergency situations-and how can the data be collected? In: Proceedings of the 1st International Conference on Evacuation Modeling and Management, The Hague, The Netherlands (2009)

Wolshon, B., Urbina, E., Wilmot, C.G., Levitan, M.: Review of policies and practices for hurricane evacuation. I: Transportation planning, preparedness, and response. Nat. Hazards Rev. 6(3), 129-142 (2005a)

Wolshon, B., Urbina, E., Wilmot, C.G., Levitan, M.: Review of policies and practices for hurricane evacuation. II: Traffic operations, management, and control. Nat. Hazards Rev. 6(3), 143-161 (2005b)

Woodworth, R.S.: Dynamics of Behavior. Holt, Rinehart and Winston, New York (1958)

Xie, C., Lin, D.Y., Waller, S.T.: A dynamic evacuation network optimization problem with lane reversal and crossing elimination strategies. Transp. Res. E 46, 295-316 (2010)

Yang, R.H., Vaughn, K.M., Abdel-Aty, M.A., Kitamura, R., Jovanis, P.P.: Design of an artificial simulator for analyzing route choice behavior in the presence of information system. Internal report RP-95-39, Institute of Transportation Studies, University of California Davis (1995)

Yuan, F., Han, L.D.: Improving evacuation planning with sensible measure of effectiveness choices-a case study. Transp. Res. Rec. 2137, 54-62 (2009)

Yuan, F., Han, L.D., Chin, S., Hwang, H.: Proposed framework for simultaneous optimization of evacuation traffic destination and route assignment. Transp. Res. Rec. 1964, 50-58 (2006)

Yusoff, M., Ariffin, J., Mohamed, A.: Optimization approaches for macroscopic emergency evacuation planning: a survey. In: Proceedings of the IEEE International Symposium on Information Technology, vol. 3, pp. 1-7 (2008)

Zelinsky, W., Kosinski, L.A.: The emergency evacuation of cities: a cross-national historical and geographical study. Rowman and Littlefield, Lanham (1991)

Zheng, H., Chiu, Y.C., Mirchandani, P.B., Hickman, M.: Modeling of evacuation and background traffic for an optimal zone-based vehicle evacuation strategy. In: Proceedings of the 89th Annual Meeting of the Transportation Research Board, Washington, DC, USA (2010)

\section{Author Biographies}

Adam J. Pel is working towards a doctoral degree at the Transport and Planning department at Delft University of Technology. His research interests are in evacuation modelling and optimization, travel behaviour modelling, (dynamic) traffic assignment, and traffic flow simulation.

Michiel C. J. Bliemer has a background in Econometrics and Operations Research, and is associate professor Transportation Modelling at Delft University of Technology in the Netherlands. Furthermore, he works at Goudappel Coffeng BV as head of innovation in transport and traffic models.

Serge P. Hoogendoorn is a professor at Traffic Management at Delft University of Technology. His research involves theory, modelling, simulation and management of traffic and transportation networks. Specific fields of interest are traffic data collection for traffic model identification, integrated network management, and traffic and mobility management in exceptional conditions. 